\title{
Looking for the next breakthrough in tobacco control and health
}

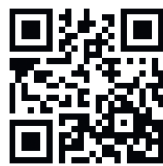

South African statistics on cigarette smoking suggest that there are grounds for some celebration on how rapidly consumption has fallen since the institution of anti-smoking policies started roughly 20 years ago. ${ }^{[1]}$ As with other countries, tax policies that increased the cost of cigarettes will have played the greatest role in the reduction in smoking. These policies have also resulted in strong economic benefits, saving up to 1.5 million lives and put over US $\$ 12.5$ billion into the economy. ${ }^{[2]}$ The authors of this paper were both very involved in achieving these policies: in 1993, Derek Yach hosted the first national meeting to brief the African National Congress on the need for stronger taxes to address tobacco use, and in that meeting David Sweanor outlined the success taxes had already achieved in his home country of Canada.
The level of continuing cigarette consumption despite all interventions to date, and the unintended consequences of these price policies (including smuggling and economic disadvantage of those unable to quit smoking), argues powerfully for a look at new breakthrough interventions. Rather than simply putting more resources into achieving diminishing returns on long established areas of intervention we need to actively look for the 'next big thing' in dealing with the health toll caused by smoking.

One of the most striking realities about tobacco control activities over the past two decades is that they fail to address the product itself. Instead, measures to date have focused on such things as where cigarettes can be sold, to whom, the price, where they can be used, what warnings must be displayed, and disclosure of toxic constituents. This oversight is rather extraordinary since we have 
known for decades that 'smokers smoke for the nicotine but die from the smoke, a point now reiterated very strongly by the Royal College of Physicians and others who call for harm-reduction principles to be applied to tobacco policy. ${ }^{[3,4]}$ This failure to address the delivery system is analogous to trying to reduce traffic fatalities while ignoring the modifiable risks in automobiles themselves.

We also know that a very significant proportion of smokers can obtain nicotine in ways that do not require the incredibly dangerous lung inhalation of the products of combustion; the process that causes them to 'die from the smoke' while they seek the nicotine they need or want. The Swedish experience with smokeless 'snus' (oral snuff) is proof-of-concept that disease risk can be massively reduced through use of a different delivery system.$^{[5]}$ The very rapidly growing global demand for electronic cigarettes (e-cigarettes) reinforces this message with what appears to be a far more acceptable product for many smokers, and even the presence of long-term users of nicotine replacement therapy (who use the products for well over a decade), shows the viability of vastly less hazardous alternatives to obtaining nicotine via smoking cigarettes.

In effect, what anti-smoking policies have done to date is to motivate smokers to want to quit, while doing exceedingly little to facilitate the sought behaviour change. To be maximally effective, policy measures must combine motivation for behaviour change with pragmatic facilitation.

The opportunity this presents for public health is hard to overstate. Sitas et al. ${ }^{[6]}$ recently indicated that tobacco deaths will remain a major contributor to the burden of disease in South Africa (SA) and in fact increase over the next few decades unless stronger action is taken. And, what is true for SA is also true globally.

There has been outstanding success in getting smokers to the point that they wish to quit, and we need to listen to them rather than continue to simply pile on dire messages, higher taxes and social isolation for those who still smoke. Smokers are clearly looking for viable options, while few are being offered. This failure to give acceptable alternatives to smokers is particularly hard to justify when we know, for instance, that genetic factors play a huge role in nicotine dependence and the ability to quit and that a great deal of smoking can be explained by self-medication with nicotine to treat a wide range of conditions. ${ }^{[7,8]}$

Further, we know that financial incentives can yield higher quit rates after 12 months than most other carefully evaluated interventions but that the best results remain quit rates of only $14 \%$ after a year. ${ }^{[9]}$ To simply give a message of abstinence is as ineffective as it is unethical. It is far easier to move consumers off smoking than to move them off nicotine, and doing so delivers nearly all of the health benefits of total cessation. ${ }^{[10]}$

We also know that in the absence of giving smokers good alternatives, they will not be idle. Cognitive dissonance will drive them to belittle their actual personal risks and to discount our package warnings. ${ }^{[1]]}$ Taxes will drive them to illicit supplies. Smokefree policies will be seen as a 'bonding experience'.

We have a chance to seize on the current market disruption being caused by e-cigarettes and to ride, rather than fight, the wave of interest among smokers. This wave shows strong signs of building as technological progress makes such products ever more acceptable to ever larger numbers of current smokers, and at prices increasingly cheaper than cigarettes. In fact, a leading Wall Street tobacco stock analyst forecasts that these products are well on their way to outselling cigarettes if we simply avoid measures that would protect combustion cigarettes from the onslaught of disruptive technology. ${ }^{[12]}$ We could well be en route to a huge global public health breakthrough on smoking-caused disease through a self-financing move by smokers themselves, one that requires little, if any, expenditure of government resources. As with other recent introductions of new technology the marketplace transition could be extremely rapid. This transition can be aided by policy measures, such as ensuring that taxes keep cigarettes more expensive than less hazardous alternatives, as crosselasticity has been shown to be a powerful force for moving smokers to alternative products. ${ }^{[13]}$

Are there risks as we embrace measures that fundamentally challenge the near-monopoly on nicotine maintenance currently held by the cigarette oligopoly? Certainly there are. They are well summarised in recent reviews. ${ }^{[14]}$ But these risks must be seen in relation to the risks of inaction (or counterproductive actions), which will inevitably mean the perpetuation of the cigarette epidemic. Would we hesitate to offer brewed tea and other caffeinated beverages to people who currently were only aware that caffeine could be obtained through the smoking of tea leaves? The biggest public health risk when simultaneously faced with an epidemic and the ability to control it is to fail to grasp the opportunity.

We can still strive for complete nicotine cessation (and products less addictive than combustion cigarettes will actually assist such a goal rather than impede it), but we are currently presented with the very real prospect of massively reducing the individual and population risks of smoking by something in the range of two orders of magnitude. If we seize the opportunity for this new breakthrough, SA can once again be on the forefront of cutting-edge health policy. For those of us personally fortunate enough to be alive and healthy in another 20 years, we could be looking at a world where the smoking of cigarettes seems as much an anachronism as trepanning. We will have finally finished the work we started 20 years ago.

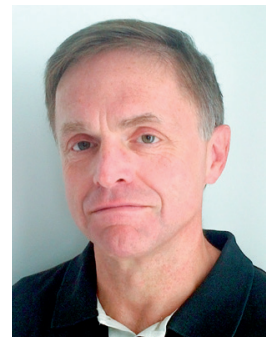

David Sweanor

Adjunct Professor, Faculty of Law, University of Ottawa, Canada; Honorary Lecturer, Division of Epidemiology and Public Health, University of Nottingham, UK dsweanor@uottawa.ca

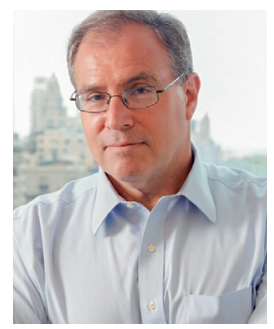

Derek Yach

Executive Director, the Vitality Institute,

New York, USA

dyach@thevitalitygroup.com

S Afr Med J 2013;103(11):810-811. DOI:10.7196/SAMJ.7513 